\title{
Pertanyaan dan nasihat dokter untuk konsumsi sayur dan buah: penelitian potong lintang pada 10 puskesmas di Yogyakarta dan Sleman
}

Physician ask and advice on vegetable and fruit consumption: a cross sectional study at ten primary health cares in Yogyakarta and Sleman

\author{
Yayi Suryo Prabandari', Bagas Suryo Bintoro², Indira Utami Yusuf ${ }^{2}$
}

\begin{abstract}
Background: Mortality caused by noncommunicable disease (NCD) has increased in the last ten years in Indonesia in line with the elevation of NCD prevalence. The NCD mortality and prevalence can be prevented by practicing healthy life style. One of healthy life style is adequate vegetable and fruit consumption that unfortunately was still far from expectation in the Basic Health Survey 2007 and 2010. Puskesmas as primary health care should anticipate the problem by encouraging doctor to routinely ask and educate on health life style. Objective: This study aimed to assess physician ask and advice on vegetable and fruit consumption based on patient and physician report. Method: Two hundred and fifty one patients from primary health care (Puskesmas) in Yogyakarta City and Sleman District participated in this cross-sectional survey. Subsequently, a survey on 57 physicians was conducted. Data were collected by structured questionnaires and exit interviews. We analyzed the data using Chi-Square test and logistic regression. Results: The results showed that patients have been asked and adviced about vegetable and fruit consumption. However, the proportion of physician report was higher than the proportion of patient's report. Patient who had gastrointestinal disorder, had body weight problem, suffered from diabetics and cardiovascular diseases were more being asked and educated about vegetable and fruit consumption than other sypmtoms or diseases. Patients who were female, not married and did not eat vegetable and fruit everyday reported more being asked and adviced by doctor on fruit and vegetable consumption than patients who were male, married and did not regularly eat fruit and vegetable. There was no difference of patient's perception on the relation between their disease and fruit and vegetables consumption based on characteristics, symptoms, disease and the frequency of eating fruit and vegetable. Conclusion: Primary health care physician has asked and adviced patient about vegetable and fruit consumption although did not routinely practice it. Delivering advice as part of patient education on high fiber diet should be included in the national insurance scheme, so that physician will routinely educate patient.
\end{abstract}

KEY WORDS: vegetable and fruit consumption, physician ask and advice, patient, primary health care

\begin{abstract}
ABSTRAK
Latar belakang: Kematian yang disebabkan oleh penyakit tidak menular (PTM) telah meningkat dalam sepuluh tahun terakhir di Indonesia sejalan dengan naiknya prevalensi PTM. Prevalensi PTM dan kematian akibat PTM dapat dicegah dengan gaya hidup sehat. Salah satu gaya hidup sehat adalah konsumsi sayur dan buah yang cukup, tetapi sayangnya konsumsi sayur dan buah masih jauh dari harapan (Riskesdas 2007 dan 2010). Puskesmas sebagai sarana pelayanan kesehatan primer sebaiknya mengantisipasi masalah tersebut dengan mendorong dokter untuk secara rutin bertanya dan memberikan nasihat gaya hidup sehat pada pasiennya. Tujuan: Mengetahui penggalian dan pemberian nasihat untuk konsumsi sayuran dan buah yang dilakukan oleh dokter berdasarkan laporan pasien dan dokter. Metode: Penelitian dengan rancangan potong lintang ini melibatkan sebanyak 251 pasien dan 57 dokter puskesmas di Kota Yogyakarta dan Kabupaten Sleman. Data dikumpulkan dengan kuesioner terstruktur dan wawancara. Data dianalisis dengan Chi-Square dan logistik regresi. Hasil: Subjek menyatakan bahwa telah ditanya dan diberi nasihat untuk mengonsumsi sayuran dan buah meskipun proporsinya berbeda dibandingkan dengan yang dilaporkan oleh dokter. Pasien yang mengalami gangguan pencernaan, mempunyai masalah berat badan, menderita diabetes, dan penyakit kardiovaskular lebih banyak ditanya dan diberi nasihat untuk mengonsumsi sayuran dan buah daripada yang tidak. Proporsi pasien perempuan, belum menikah, dan tidak konsumsi sayur dan buah setiap hari, lebih banyak yang ditanya dan disarankan tentang konsumsi buah dan sayur daripada pria, telah menikah, dan hanya kadang-kadang mengonsumsi sayur dan buah. Tidak ada perbedaan persepsi pasien terhadap hubungan antara penyakit yang diderita dengan konsumsi sayur dan buah berdasarkan karakteristik, keluhan, diagnosis, dan frekuensi konsumsi sayur dan buah. Simpulan: Dokter di puskesmas telah bertanya dan memberi nasihat tentang konsumsi
\end{abstract}

\footnotetext{
Korespondensi: Bagian Ilmu Kesehatan Masyarakat, Fakultas Kedokteran Universitas Gadjah Mada, Jl. Farmako, Sekip Utara, Yogyakarta 55281, e-mail: yayisuryo@ ugm.ac.id

2 Fakultas Kedokteran Universitas Gadjah Mada, Jl. Farmako, Sekip Utara, Yogyakarta 55281
} 
sayur dan buah meskipun tidak secara rutin. Pemberian nasihat tentang konsumsi sayur dan buah sebagai bagian dari edukasi pasien harusnya masuk dalam skema Sistem Jaminan Sosial Nasional (SJSN) sehingga dokter dapat melakukannya secara teratur.

KATA KUNCI: konsumsi sayur dan buah, pertanyaan dan nasihat dokter, pasien, puskesmas

\section{PENDAHULUAN}

Indonesia menghadapi beban ganda malnutrisi atau double burden of malnutrition (DBM) (1). Gizi buruk telah menurun prevalensinya di Indonesia, tetapi stunting masih berada pada peringkat 5 terbanyak di dunia dan wasting berada di posisi 10 prevalensi tertinggi di dunia. Survei Kehidupan Rumah Tangga Indonesia (IFLS) yang mewakili $85 \%$ populasi (1) menunjukkan bahwa selama periode 15 tahun, proporsi laki-laki dan perempuan kurus mengalami penurunan yang signifikan sedangkan proporsi laki-laki dan perempuan gemuk (berat badan lebih) meningkat hampir dua kalinya. Riset kesehatan dasar (Riskesdas) 2007 (2) dan 2010 (3) juga menunjukkan kenaikan prevalensi berat badan (BB) lebih dan obese pada usia dewasa, yaitu BB lebih sebanyak 8,8\% di tahun 2007 menjadi 10,0\% pada tahun 2010 dan prevalensi kegemukan (obese) dari 10,3\% tahun 2007 menjadi $11,7 \%$ di tahun 2010.

Dalam Riskesdas 2007 (2) dilaporkan bahwa prevalensi penyakit tidak menular (PTM) telah menyusul prevalensi penyakit menular. Stroke merupakan prevalensi tertinggi (26,9\%) disusul hipertensi (12,3\%) dan diabetes (10,2\%). Proporsi tertinggi penyakit penyebab kematian di Indonesia telah bergeser dari penyakit infeksi ke PTM sejak tahun 1995. Pergeseran pola penyakit yang terjadi di Indonesia tersebut mengikuti transisi epidemiologi global (4). Pada tahun 2012, World Health Organization (WHO) (5) melaporkan bahwa dalam satu dekade, dari tahun 2000-2011 di seluruh dunia terjadi kenaikan 10 penyebab utama kematian yang didominasi oleh PTM. Penyakit jantung iskemik merupakan penyebab pertama kemudian disusul stroke, penyakit paru obstruktif kronik (PPOK), dan diabetes. Pola ini terdapat di semua negara tanpa memandang sosial ekonomi negara tersebut (6). Lebih dari $60 \%$ kematian di Indonesia diakibatkan oleh PTM dengan urutan penyebab terbanyak adalah penyakit kardiovaskuler $(30 \%)$, kanker (13\%), penyakit respiratori (7\%), dan diabetes (3\%) (7). Kenaikan PTM dapat dikendalikan melalui perubahan gaya hidup seperti menggiatkan aktivitas olahraga, memperbaiki pola makan, mengurangi konsumsi alkohol, dan tidak merokok
(8). Oleh karena itu, dalam WHO NCD action plan ketiga disebutkan bahwa secara global setiap negara sebaiknya melakukan intervensi untuk keempat faktor risiko PTM yang dapat dimodifikasi tersebut (9).

Faktor risiko PTM yang terjadi di Indonesia menurut Riskesdas 2007 adalah perilaku merokok sebesar $34,7 \%$ (laki-laki $65,9 \%$ dan perempuan $4,2 \%$ ), kurang makan sayur dan buah (kurang dari 5 porsi/hari selama 7 hari dalam seminggu) sebesar 93,6\% (laki-laki 93,5\% dan perempuan 93,7\%), dan kurang aktivitas fisik (kegiatan kumulatif aktivitas fisik kurang dari 150 menit/minggu) sebesar $48,2 \%$ (laki-laki $41,4 \%$ dan perempuan $54,5 \%$ ) (2). Berdasarkan ketiga gaya hidup tersebut, kurang makan sayur dan buah merupakan prevalensi tertinggi untuk gaya hidup kurang sehat. Meskipun kampanye untuk mengonsumsi makanan dan minuman menyehatkan sudah dilakukan sejak beberapa dekade di Indonesia, mulai dari slogan "empat sehat lima sempurna" sampai dengan "13 pesan umum gizi seimbang" (10). Namun, asupan gizi yang memenuhi kesehatan masih menjadi masalah kesehatan masyarakat di Indonesia.

Edukasi untuk konsumsi sayur dan buah membutuhkan intervensi promosi kesehatan yang menyeluruh. Selain melalui kampanye, edukasi massa, dan komunikasi kesehatan, pendekatan edukasi personal melalui profesional kesehatan terutama di pelayanan primer (11) diperlukan untuk lebih mempercepat pengubahan gaya hidup sehat. Hasil penelitian di Belanda (12) melaporkan bahwa dokter pelayanan primer mempunyai peran penting dalam menginisiasi dan mendorong perubahan pola makan. Di samping itu, dokter pelayanan primer merupakan profesional kesehatan yang berinteraksi langsung dengan masyarakat. Dokter pelayanan primer diharapkan memberikan nasihat dan edukasi tentang pola makan sehat karena penelusuran perilaku berisiko kesehatan, kebiasaan, dan gaya hidup serta nasihat ataupun edukasi terhadap hal tersebut merupakan bagian komunikasi dokter dan pasien (13). Dokter juga merupakan profesional kesehatan yang dipercaya untuk menyampaikan nasihat medis (14) 
karena pasien pun berharap mendapatkan nasihat (9). Sedikit berbeda dengan hasil penelitian di Belanda, pasien di Indonesia dilaporkan membutuhkan kerja sama dengan dokter dan tidak hanya sekedar konsultasi atau nasihat (15).

Sebagai ujung tombak pelayanan kesehatan di Indonesia, terlebih lagi dalam era Sistem Jaminan Sosial Nasional (SJSN) yang akan dimulai awal tahun 2014, dokter pelayanan primer sudah seharusnya memberikan nasihat atau edukasi tentang hidup sehat agar pasiennya dapat memodifikasi perilaku tidak sehatnya. Edukasi penting untuk meningkatkan pengetahuan pasien, untuk kemudian dari pemahaman ini muncul kepercayaan dan akan membawa pasien untuk patuh mengikuti nasihat dokter (16). Agar dapat memberikan nasihat dan edukasi dengan tepat, penelusuran riwayat gaya hidup perlu dilakukan secara mendalam dan lengkap $(17,18)$. Bagaimana persepsi pasien terhadap pertanyaan dan nasihat dokter tentang kebiasaan hidup sehat, salah satunya adalah pola konsumsi sayur dan buah pada pasien di pelayanan primer di Indonesia khususnya Yogyakarta dan Sleman belum banyak diketahui. Penelitian ini bertujuan untuk 1) mendeskripsikan pola dokter bertanya dan memberikan nasihat tentang konsumsi sayur dan buah di Puskesmas Kota Yogyakarta dan Sleman berdasarkan laporan dokter dan pasien; 2) mengetahui prediktor pasien ditanya dan dinasihati oleh dokter; dan 3) mengetahui prediktor persepsi pasien tentang hubungan antara penyakit yang dideritanya dengan frekuensi makan sayur dan buah.

\section{BAHAN DAN METODE}

Penelitian ini adalah bagian dari penelitian pengembangan kapasitas dokter dalam edukasi pasien untuk pengendalian penyakit yang berkaitan dengan gaya hidup di pelayanan primer. Jenis penelitian adalah noneksperimen dengan rancangan potong lintang yang dilakukan pada akhir tahun 2011. Populasi penelitian ini adalah pasien yang datang di Puskesmas Kota Yogyakarta dan Sleman. Sampel sebanyak 251 pasien dipilih dengan kuota sampling dan pasien yang bersedia menjadi subjek penelitian langsung diwawancara setelah keluar dari ruang pemeriksaan di puskesmas. Survei pada dokter dilakukan pada 57 dokter di puskesmas yang sama dengan survei pasien dan sampel diambil menggunakan metode sampling kluster. Enam dari 25 puskesmas di Sleman serta 4 dari 18 puskesmas di Kota Yogyakarta dipilih secara proporsioal dengan pertimbangan keterwakilan wilayah Kabupaten Sleman dan Kota Yogyakarta.

Data dikumpulkan melalui wawancara berdasarkan kuesioner terstruktur dan dokter mengisi sendiri kuesionernya. Kedua kuesioner diadopsi dari kuesioner perilaku merokok dokter dan masyarakat proyek Quit Tobacco Indonesia (QTI) Fakultas Kedokteran Universitas Gadjah Mada (FK UGM) dan pertanyaan dalam Riskesdas 2007. Sebelum digunakan, kuesioner diuji keterbacaannya pada 2 dokter dan 5 masyarakat umum untuk menguji validitas muka (face validity). Peneliti tidak melakukan uji construct validity karena kuesioner terdiri dari pertanyaan faktual.

Variabel bebas pada penelitian ini adalah karakteristik pasien (jenis kelamin, usia, dan status perkawinan), keluhan dan diagnosis yang diberitahukan oleh dokter pada pasien serta konsumsi sayur dan buah. Variabel keluhan diketahui dengan menanyakan gejala yang dirasakan oleh pasien sehingga berobat ke puskesmas. Variabel diagnosis yang disampaikan pada pasien ditanyakan dengan "Apakah pasien dinyatakan dokter menderita hipertensi atau diabetes? (dan penyakit lainnya, yang dalam penelitian ini hanya diambil persentase terbanyak)".

Variabel konsumsi sayur dan buah diadopsi dari pertanyaan Riskesdas 2007. Responden ditanya berdasarkan frekuensi konsumsi sayur dan buah dalam sehari dengan pilihan jawaban yaitu tidak mengonsumsi setiap hari, 1 porsi/hari, 2 porsi/hari, 3 porsi/hari, dan lebih dari 3 porsi/hari. Pertanyaan diajukan dalam kuesioner dan tidak dilakukan food recall ataupun food frequency questionnaire (FFQ). Variabel terikat atau hasil (outcome variable) adalah pertanyaan dan nasihat dokter tentang gaya hidup sehat dan persepsi pasien tentang hubungan antara konsumsi sayur dan buah dengan penyakit yang diderita (Tabel 1). Data dianalisis dengan software STATA for Windows, Version 12.0 lisensi Program Studi S2 Ilmu Kesehatan Masyarakat FK UGM. Uji yang digunakan adalah Chi-Square dan logistik regresi. Penelitian dilakukan setelah mendapatkan persetujuan dari Komisi Etik FK UGM dengan nomor surat KE/FK/776/EC. 
Yayi Suryo Prabandari, dkk: Pertanyaan dan nasihat dokter untuk konsumsi sayur dan buah: penelitian potong lintang pada 10 puskesmas

Tabel 1. Variabel hasil (outcome variable)

\begin{tabular}{lll}
\hline \multicolumn{1}{c}{ Variabel } & \multicolumn{2}{c}{ Pertanyaan pada kuesioner } \\
\cline { 2 - 3 } & \multicolumn{1}{c}{ Dokter } & \multicolumn{1}{c}{ Pasien } \\
\hline Dokter bertanya pada pasien & $\begin{array}{l}\text { Apakah Anda menanyakan kebiasaan } \\
\text { mengonsumsi buah dan sayur pada pasien } \\
\text { Anda? }\end{array}$ & $\begin{array}{l}\text { Apakah dokter menanyakan kebiasaan } \\
\text { Anda mengonsumsi buah dan sayur? }\end{array}$ \\
$\begin{array}{l}\text { Dokter memberikan nasihat pada } \\
\text { pasien }\end{array}$ & $\begin{array}{l}\text { Apakah Anda menganjurkan pada pasien Anda } \\
\text { untuk mengonsumsi buah dan sayur secara } \\
\text { teratur? }\end{array}$ & $\begin{array}{l}\text { Apakah dokter menganjurkan pada Anda } \\
\text { untuk mengonsumsi buah dan sayur secara } \\
\text { teratur? }\end{array}$ \\
Keharusan dokter bertanya & \multicolumn{1}{c}{$\begin{array}{l}\text { Menurut Anda, apakah dokter harus } \\
\text { perlu bertanya tentang kebiasaan Anda } \\
\text { mengonsumsi buah dan sayur? }\end{array}$} \\
$\begin{array}{l}\text { Persepsi pasien tentang kaitan } \\
\text { antara penyakitnya dengan } \\
\text { konsumsi buah dan sayur }\end{array}$ & ---- tidak ditanyakan ----- & $\begin{array}{l}\text { Apakah menurut Anda penyakit Anda } \\
\text { berhubungan dengan konsumsi buah dan } \\
\text { sayur? }\end{array}$ \\
\hline
\end{tabular}

Tabel 2. Karakteristik pasien serta konsumsi sayur dan buah berdasarkan jenis kelamin

\begin{tabular}{llcccc}
\hline \multirow{2}{*}{ Karakteristik } & & \multicolumn{2}{c}{ Laki - laki } & \multicolumn{2}{c}{ Perempuan } \\
\cline { 3 - 6 } & & $\mathbf{n}$ & $\mathbf{\%}$ & $\mathbf{n}$ & $\mathbf{\%}$ \\
\hline \multirow{3}{*}{ Umur (tahun) } & $<45$ & 51 & 46,4 & 71 & 50,9 \\
& $>45$ & 60 & 53,6 & 69 & 49,1 \\
& Ya & 82 & 73,9 & 107 & 76,4 \\
\multirow{5}{*}{ Frekuensi makan sayur dan buah } & Tidak & 23 & 20,7 & 19 & 13,6 \\
& Janda/duda & 6 & 5,4 & 14 & 10,0 \\
& Tidak setiap hari & 24 & 21,6 & 21 & 15,0 \\
& 1 porsi/hari & 34 & 30,7 & 38 & 27,1 \\
& 2 porsi/hari & 25 & 22,5 & 36 & 25,8 \\
& 3 porsi/hari & 26 & 23,4 & 43 & 30,7 \\
& $>3$ porsi/hari & 2 & 1,8 & 2 & 1,4 \\
\hline
\end{tabular}

\section{HASIL}

Sebanyak 251 pasien (140 atau 55,8\% perempuan dan 111 atau 44,2\% laki-laki) dan 57 dokter (46 atau 80,7\% perempuan dan 11 atau 19,3\% laki-laki) yang berasal dari 6 puskesmas di Kabupaten Sleman dan 4 puskesmas di Kota Yogyakarta berpartisipasi dalam penelitian ini. Karakteristik pasien dan frekuensi mengonsumsi buah dan sayur terlihat pada Tabel 2. Perbandingan jumlah pasien laki-laki dan perempuan dalam penelitian ini cukup seimbang meskipun pasien perempuan lebih banyak. Status menikah pasien tidak terlalu berbeda, meskipun laki-laki yang tidak menikah lebih banyak daripada perempuan. Seperti ditunjukkan pada Tabel $\mathbf{2}$, terdapat perbedaan pada frekuensi makan sayur dan buah dalam sehari antara laki-laki dan perempuan. Lebih banyak pasien laki-laki yang tidak mengonsumsi sayur dan buah setiap hari dibandingkan perempuan serta proporsi terbanyak pada laki-laki adalah mengonsumsi sayur dan buah 1 porsi sehari, sementara pada pasien perempuan adalah 3 porsi sehari. Responden dokter pada penelitian sebagian besar perempuan $(80,7 \%)$ dan sudah menikah $(84,2 \%)$.

Tabel 3 menunjukkan bahwa sepertiga pasien pernah ditanya oleh dokter tentang kebiasaan mengonsumsi sayur dan buah. Sementara itu, sebagian besar dokter melaporkan telah bertanya tentang konsumsi sayur dan buah, meskipun $63 \%$ diantaranya tidak rutin menanyakan dan $67 \%$ hanya kadang-kadang menanyakan frekuensi mengonsumsinya. Menurut hampir $80 \%$ pasien, dokter seharusnya menanyakan tentang kebiasaan pasien mengonsumsi sayur dan buah. Nasihat untuk makan sayur dan buah dilaporkan hampir pada $40 \%$ pasien. Hasil ini serupa dengan yang dilaporkan oleh dokter bahwa sebesar $44 \%$ rutin (hampir selalu dan selalu) memberikan nasihat tentang sayur dan buah.

Tabel 4 menunjukkan bahwa tidak semua pasien ditanya dan dinasihati tentang kebiasaan mengonsumsi sayur dan buah. Pasien yang memiliki masalah dengan 
Tabel 3. Pertanyaan dan nasihat dokter tentang konsumsi sayur dan buah menurut pasien dan dokter

\begin{tabular}{|c|c|c|c|c|c|}
\hline \multirow{2}{*}{ Pertanyaan } & & \multicolumn{2}{|c|}{ Dokter $(n=57)$} & \multicolumn{2}{|c|}{ Pasien $(n=251)$} \\
\hline & & $\mathbf{n}$ & $\%$ & $\mathbf{n}$ & $\%$ \\
\hline \multicolumn{6}{|l|}{ Dokter bertanya pada pasien } \\
\hline \multirow{5}{*}{$\begin{array}{l}\text { Menanyakan tentang kebiasaan mengonsumsi sayur } \\
\text { dan buah }\end{array}$} & Tidak pernah & 3 & 5,3 & 170 & 67,7 \\
\hline & Ya & & & 81 & 32,3 \\
\hline & Kadang-kadang & 36 & 63,2 & & \\
\hline & Hampir selalu & 14 & 24,5 & & \\
\hline & Selalu & 4 & 7,0 & & \\
\hline \multirow[t]{4}{*}{ Menanyakan tentang frekuensi makan sayur } & Tidak pernah & 7 & 12,2 & & \\
\hline & Kadang-kadang & 38 & 66,7 & & \\
\hline & Hampir selalu & 9 & 16,7 & & \\
\hline & Selalu & 3 & 5,3 & & \\
\hline \multicolumn{6}{|l|}{ Keharusan dokter bertanya } \\
\hline \multirow{3}{*}{$\begin{array}{l}\text { Dokter seharusnya menanyakan konsumsi sayur dan } \\
\text { buah }\end{array}$} & Ya & & & 196 & 78,1 \\
\hline & Tidak & & & 52 & 20,7 \\
\hline & Tidak tahu & & & 3 & 1,1 \\
\hline \multicolumn{6}{|l|}{ Dokter memberikan nasihat pada pasien } \\
\hline \multirow[t]{5}{*}{ Memberikan nasihat tentang makan sayur dan buah } & Tidak pernah & 3 & 5,2 & 153 & 61,0 \\
\hline & Ya & & & 98 & 39,0 \\
\hline & Kadang-kadang & 29 & 50,9 & & \\
\hline & Hampir selalu & 20 & 35,1 & & \\
\hline & Selalu & 5 & 8,8 & & \\
\hline
\end{tabular}

Tabel 4. Jenis pasien yang ditanya dan dinasihati untuk konsumsi sayur dan buah

\begin{tabular}{lcccc}
\hline \multirow{2}{*}{ Jenis pasien } & \multicolumn{2}{c}{ Ditanya oleh dokter } & \multicolumn{2}{c}{ Dinasihati oleh dokter } \\
\cline { 2 - 5 } & $\mathbf{n}$ & $\mathbf{\%}$ & $\mathbf{n}$ & $\mathbf{\%}$ \\
\hline Semua pasien & 9 & 16,7 & 13 & 22,8 \\
Pasien yang memiliki masalah berat badan & 41 & 75,9 & 36 & 63,2 \\
Pasien dengan gangguan pernafasan & 6 & 11,1 & 8 & 14,0 \\
Pasien dengan gangguan kardiovaskuler & 25 & 46,3 & 27 & 47,4 \\
Pasien dengan diabetes & 36 & 66,7 & 36 & 63,2 \\
Pasien dengan gangguan pencernaan & 43 & 75,4 & 38 & 66,7 \\
\hline
\end{tabular}

berat badan, gangguan pencernaan, diabetes, dan kardiovaskuler adalah pasien dengan urutan proporsi terbanyak ditanya dan dinasihati oleh dokter.

Tabel 5 menunjukkan bahwa karakteristik pasien bukan prediktor dalam dokter bertanya dan memberi nasihat tentang konsumsi sayur dan buah. Justru pasien yang mengonsumsi buah dan sayur 2 porsi dan lebih dari 3 porsi sehari menyebabkan dokter tidak bertanya atau memberikan nasihat tentang konsumsi buah dan sayur. Pasien perempuan, usia kurang dari 45 tahun, tidak menikah, dan tidak konsumsi sayur dan buah adalah pasien yang lebih ditanya dan dinasihati dokter untuk mengonsumsi sayur dan buah, meskipun tidak bermakna secara statistik. Hanya sepertiga pasien yang didiagnosis dokter mengalami hipertensi dan diabetes ditanya dokter tentang konsumsi sayur dan buah, sementara yang dinasihati hampir separuhnya.

Tabel 6 juga menunjukkan bahwa karakteristik pasien bukan merupakan prediktor persepsi pasien tentang hubungan antara penyakitnya dengan konsumsi sayur dan buah. Secara keseluruhan, sebanyak 48\% pasien menyatakan bahwa ada hubungan antara konsumsi sayur dan buah dengan penyakit yang dideritanya. Bila berdasarkan karakteristik, pasien perempuan, usia kurang dari 45 tahun, dan tidak menikah mempunyai persepsi yang lebih tinggi akan hubungan penyakit dengan konsumsi sayur dan buah. Pasien yang didiagnosis diabetes lebih mengasosiasikan penyakitnya dengan 
Yayi Suryo Prabandari, dkk: Pertanyaan dan nasihat dokter untuk konsumsi sayur dan buah: penelitian potong lintang pada 10 puskesmas

Tabel 5. Prediktor dokter bertanya dan memberi nasihat pada pasien tentang konsumsi sayur dan buah

\begin{tabular}{|c|c|c|c|c|c|c|c|}
\hline & \multirow[t]{2}{*}{ Variabel } & \multicolumn{2}{|c|}{$\begin{array}{c}\text { Dokter bertanya } \\
(\%)\end{array}$} & \multirow[t]{2}{*}{$\begin{array}{c}\text { OR } \\
(95 \% \mathrm{CI})\end{array}$} & \multicolumn{2}{|c|}{$\begin{array}{c}\text { Dokter memberi nasihat } \\
\text { pada pasien } \\
(\%)\end{array}$} & \multirow[t]{2}{*}{$\begin{array}{c}\text { OR } \\
(95 \% \mathrm{CI})\end{array}$} \\
\hline & & Ya & Tidak & & Ya & Tidak & \\
\hline \multirow[t]{2}{*}{ Umur } & $<45$ tahun & 34 & 66 & 1 & 40 & 60 & 1 \\
\hline & $>45$ tahun & 27 & 73 & $\begin{array}{c}1,4 \\
(0,76-2,54)\end{array}$ & 33 & 67 & $\begin{array}{c}0,7 \\
(0,41-1,31)\end{array}$ \\
\hline \multirow[t]{2}{*}{ Jenis kelamin } & Laki-laki & 27 & 73 & 1 & 37 & 63 & 1 \\
\hline & Perempuan & 35 & 65 & $\begin{array}{c}1,45 \\
(0,79-2,65)\end{array}$ & 41 & 59 & $\begin{array}{c}1,2 \\
(0,68-2,13)\end{array}$ \\
\hline \multirow{3}{*}{$\begin{array}{l}\text { Status } \\
\text { perkawinan }\end{array}$} & Menikah & 32 & 68 & 1 & 40 & 60 & 1 \\
\hline & Tidak menikah & 33 & 67 & $\begin{array}{c}1,04 \\
(0,58-1,88)\end{array}$ & 43 & 57 & $\begin{array}{c}1,1 \\
(0,64-1,98)\end{array}$ \\
\hline & Janda/duda & 25 & 75 & $\begin{array}{c}0,7 \\
(0,38-1,30)\end{array}$ & 25 & 75 & $\begin{array}{c}0,5 \\
(0,27-0,91)\end{array}$ \\
\hline Keluhan & Tekanan darah tinggi & 26 & 64 & & 43 & 57 & \\
\hline \multirow[t]{2}{*}{ Diagnosis } & Hipertensi & 33 & 67 & & 46 & 54 & \\
\hline & Diabetes & 33 & 67 & & 53 & 47 & \\
\hline \multirow{5}{*}{$\begin{array}{l}\text { Frekuensi } \\
\text { makan sayur }\end{array}$} & Tidak setiap hari & 42 & 58 & 1 & 40 & 60 & 1 \\
\hline & 1 porsi/hari & 35 & 65 & $\begin{array}{c}0,7 \\
(0,42-1,31)\end{array}$ & 38 & 62 & $\begin{array}{c}0,9 \\
(0,52-1,61)\end{array}$ \\
\hline & 2 porsi/hari & 21 & 79 & $\begin{array}{c}0,3 \\
(0,18-0,7)^{*}\end{array}$ & 33 & 66 & $\begin{array}{c}0,7 \\
(0,42-1,33)\end{array}$ \\
\hline & 3 porsi/hari & 29 & 81 & $\begin{array}{c}0,49 \\
(0,26-0,88)\end{array}$ & 46 & 54 & $\begin{array}{c}1,2 \\
(0,73-2,23)\end{array}$ \\
\hline & $>3$ porsi/hari & 25 & 75 & $\begin{array}{c}0,46 \\
(0,25-0,83)^{*}\end{array}$ & 33 & 67 & $\begin{array}{c}0,73 \\
(0,41-1,31)\end{array}$ \\
\hline
\end{tabular}

Keterangan: * = bermakna $(\mathrm{p}<0,05)$

Tabel 6. Prediktor persepsi pasien terhadap hubungan antara penyakit yang diderita dengan konsumsi buah dan sayur

\begin{tabular}{|c|c|c|c|c|}
\hline & \multirow[t]{2}{*}{ Variabel } & \multicolumn{2}{|c|}{$\begin{array}{l}\text { Persepsi pasien terhadap hubungan penyakit } \\
\text { dengan konsumsi serat }(\%)\end{array}$} & \multirow{2}{*}{$\begin{array}{c}\text { OR } \\
(95 \% \text { CI })\end{array}$} \\
\hline & & Ya & Tidak & \\
\hline \multirow[t]{2}{*}{ Umur (tahun) } & $<45$ & 57 & 43 & 1 \\
\hline & $>45$ & 49 & 51 & $0,7(0,41-1,26)$ \\
\hline \multirow[t]{2}{*}{ Jenis } & Laki-laki & 50 & 50 & 1 \\
\hline & Perempuan & 58 & 42 & $1,3(0,79-2,40)$ \\
\hline \multirow[t]{3}{*}{ Status } & Menikah & 54 & 46 & 1 \\
\hline & Tidak menikah & 60 & 40 & $1,2(0,73-2,24)$ \\
\hline & Janda/duda & 55 & 45 & $1,04(0,59-1,81)$ \\
\hline Keluhan & Tekanan darah tinggi & 51 & 49 & \\
\hline \multirow[t]{2}{*}{ Diagnosis } & Hipertensi & 56 & 44 & 1 \\
\hline & Diabetes & 63 & 37 & $1,3(076-2,31)$ \\
\hline \multirow{5}{*}{$\begin{array}{l}\text { Frekuensi } \\
\text { makan sayur }\end{array}$} & Tidak setiap hari & 56 & 44 & 1 \\
\hline & 1 porsi/hari & 54 & 46 & $0,9(0,52-1,60)$ \\
\hline & 2 porsi/hari & 54 & 46 & $0,9(0,52-1,60)$ \\
\hline & 3 porsi/hari & 56 & 44 & 1 \\
\hline & $>3$ porsi/hari & 50 & 50 & $0,78(0,45-1,31)$ \\
\hline
\end{tabular}


Tabel 7. Frekuensi konsumsi sayur dan buah berdasar karakteristik, keluhan, dan diagnosis

\begin{tabular}{llccccc}
\hline & \multirow{2}{*}{ Variabel } & \multicolumn{5}{c}{ Frekuensi makan sayur dan buah (\%) } \\
\cline { 3 - 6 } & & Tidak & $\mathbf{1 x} / \mathbf{h a r i}$ & $\mathbf{2 x} / \mathbf{h a r i}$ & $\mathbf{3 x} / \mathbf{h a r i}$ & $\mathbf{3 \mathbf { 3 x }} / \mathbf{h a r i}$ \\
\hline \multirow{2}{*}{ Umur (tahun) } & $<45$ & 16,7 & 30,4 & 22,5 & 26,5 & 3,9 \\
\multirow{3}{*}{ Status } & $\geq 45$ & 15,7 & 25,9 & 27,8 & 30,6 & 0 \\
& Menikah & 17 & 27 & 22 & 31 & 2,1 \\
& Tidak menikah & 23,8 & 33,3 & 23 & 19 & 0 \\
\multirow{3}{*}{ Keluhan } & Janda/duda & 15 & 35 & 40 & 10 & 0 \\
Diagnosis & Tekanan darah tinggi & 14,3 & 20 & 31,4 & 34,3 & 0 \\
& Hipertensi & 14 & 28 & 28 & 30 & 0 \\
& Diabetes & 10 & 23 & 23 & 43 & 0 \\
\hline
\end{tabular}

konsumsi sayur dan buah daripada pasien yang didiagnosis hipertensi. Sementara itu, pasien yang mengonsumsi sayur dan buah lebih dari 3 kali sehari adalah yang paling tidak mengasosiasikan konsumsi sayur buah dengan penyakit.

Tabel 7 menunjukkan bahwa pasien janda atau duda lebih sering mengonsumsi sayur dan buah daripada pasien yang telah menikah atau yang tidak menikah. Pasien yang berusia lebih dari atau sama dengan 45 tahun, memiliki keluhan tekanan darah tinggi, dan didiagnosis dokter mengalami diabetes dan hipertensi, sebagian besar melaporkan bahwa mengonsumsi sayur dan buah lebih dari 3 kali sehari.

\section{BAHASAN}

Hasil penelitian menunjukkan bahwa frekuensi mengonsumsi sayur dan buah lebih sering dilakukan oleh perempuan. Konsumsi sayur dan buah lebih dari 3 porsi sehari masih di bawah $2 \%$, baik pada laki-laki maupun perempuan. Hasil ini tidak jauh berbeda dari angka prevalensi nasional yang menunjukkan konsumsi sayur dan buah yang kurang di Indonesia masih di atas 90\% (2). Apabila dilihat dari konsumsi sayur dan buah sebanyak 3 porsi sehari, persentase perempuan yang melakukannya (30\%) sedikit lebih banyak daripada laki-laki (23\%). Rendahnya proporsi pasien yang mengonsumsi sayur dan buah dalam porsi yang memadai dapat disebabkan oleh pesan gizi yang disosialisasikan sejak satu dekade terkahir tidak mudah dipahami. Dalam Pesan Umum Gizi Seimbang (PUGS) (19) yang digambarkan dengan bentuk kerucut (tumpeng), di samping buah dan sayur dituliskan 3-5 porsi. Penjelasan 3-5 porsi hanya terdapat pada buku panduan untuk petugas sehingga adanya pesan 3-5 porsi tersebut dalam gambar dapat menyebabkan kebingungan bagi masyarakat.

Hasil penelitian terhadap 13 PUGS di beberapa provinsi menunjukkan bahwa separuh partisipan tidak paham pesan tentang porsi tersebut (10). Porsi yang dimaksud di dalam pesan tersebut menimbulkan persepsi yang berbeda-beda. Lebih lanjut, dalam wawancara dengan salah satu dokter puskesmas di tempat penelitian, peneliti mendapatkan informasi bahwa pada saat pasien diberi edukasi untuk mengonsumsi sayur dan buah, pasien menjawab bahwa harga sayur dan buah mahal sehingga mereka memilih lauk berupa gorengan untuk menu makan utama karena tempe, tahu, bakwan, dan aneka bahan yang digoreng lebih murah. Makanan yang digoreng dan banyak dijual di daerah Yogyakarta dan sekitarnya merupakan makanan yang asin dan berlemak. Hal ini sesuai dengan fakta bahwa konsumsi makanan asin dan berlemak di Yogyakarta tahun 2007 berturut-turut sebesar $13,2 \%$ dan $14,2 \%$ (2).

Anamnesis atau dokter yang bertanya secara rutin (hampir selalu dan selalu) kepada pasien terkait kebiasaan makan buah dan sayur adalah sebesar 31,5\%. Hasil ini sesuai dengan yang dilaporkan oleh pasien yaitu sebanyak $32,3 \%$ yang pernah ditanya oleh dokter tentang kebiasaan mengonsumsi sayur dan buah. Selanjutnya, untuk edukasi atau menasihati pasien agar mengonsumsi sayur dan buah secara rutin, dokter melaporkan sedikit lebih tinggi (43,9\%) daripada yang dilaporkan pasien (39\%). Hasil penelitian ini serupa dengan penelitian di Kanada (20)yaitu sebanyak 38\% pasien melaporkan telah diberi nasihat untuk pengaturan makan. Penelitian di Belanda (8) juga melaporkan bahwa dalam kurun waktu 1975-2008, dokter pelayanan primer 
yang mendiskusikan tentang nutrisi sebesar 7,5\%-13,1\% dengan rerata $10,3 \%$. Selain itu, hasil penelitian di Amerika (21) berdasarkan kunjungan ke dokter pada 184.668.007 pasien yang didiagnosis diabetes tipe 2 , hipertensi atau obesitas, dan lebih dari 140 juta pasien dengan insulin, diperoleh hasil bahwa lebih dari tiga perempat pasien yang datang ke dokter tersebut tidak mendapatkan konseling atau edukasi mengenai gaya hidup. Sementara itu, hampir $80 \%$ pasien menyatakan bahwa dokter seharusnya bertanya mengenai kebiasaan pasien mengonsumsi sayur dan buah. Pasien tidak hanya ingin dokternya bertanya, tetapi juga diberi nasihat dan diajak bekerja sama menyelesaikan masalah kesehatannya $(16,15)$.

Harapan pasien bahwa dokter seharusnya bertanya, memberi nasihat, dan dapat bekerja sama untuk menyelesaikan masalahnya merupakan hal yang perlu mendapatkan perhatian yang serius, mengingat penelitian ini dilakukan di puskesmas. Berdasarkan pengamatan peneliti, pasien bertemu dengan dokter di puskesmas hanya dalam waktu singkat karena banyaknya pasien dan panjangnya antrian sehingga harapan tersebut kemungkinan tidak dapat terpenuhi. Perlu dipikirkan suatu sistem atau alur yang memungkinkan data atau informasi pasien tentang gaya hidup tetap ditelusur lengkap dan pasien mendapatkan nasihat serta bisa berdiskusi dengan dokter di pelayanan primer.

Dalam penelitian ini juga ditemukan bahwa anamnesis atau pertanyaan dan nasihat dokter tentang kebiasaan mengonsumsi sayur dan buah yang tertinggi terdapat pada pasien dengan masalah berat badan dan gangguan pencernaan, disusul pada pasien dengan diabetes dan gangguan kardiovaskular. Hasil ini serupa dengan penelitian sebelumnya yang menyatakan bahwa pasien dengan keluhan digestif(32,5\%), disusul dengan keluhan sirkulatori $(10,4 \%)$, respiratori, dan metabolik yang diajak berdiskusi tentang nutrisi oleh dokter pelayanan primer di Belanda (9). Masih rendahnya persentase pasien yang ditanya ataupun dinasihati tentang nutrisi yang sehat ini dapat disebabkan oleh keyakinan diri dokter untuk memberikan nasihat, edukasi atau konseling nutrisi yang masih belum kuat karena belum dilatih secara adekuat (21). Pemberian nasihat dan konseling tentang nutrisi dan olahraga merupakan komponen utama dalam pencegahan diabetes dan penyakit jantung koroner (22).
Pasien perempuan, usia kurang dari 45 tahun, dan pasien yang tidak menikah dalam penelitian ini lebih banyak ditanya dan dinasihati dokter untuk mengonsumsi sayur dan buah. Jumlah pasien dengan diagnosis dari dokter sebagai pasien diabetes dan hipertensi yang ditanya tentang kebiasaan mengonsumsi sayur dan buah menunjukkan persentase yang sama. Namun, pasien yang menerima nasihat untuk mengonsumsi sayur dan buah lebih tinggi pada pasien dengan diabetes. Pasien dengan keluhan tekanan darah tinggi lebih banyak dinasihati daripada ditanya tentang kebiasaan mengonsumsi sayur dan buah. Pola ini terlihat sama pada semua karakteristik pasien dan frekuensi pasien dalam mengonsumsi sayur dan buah, lebih banyak pasien yang melaporkan dinasihati daripada ditanya tentang konsumsi sayur dan buah. Hasil penelitian ini sedikit berbeda dengan yang dilakukan di Kanada (23) karena pada penelitian tersebut pasien laki-laki, usia 35-64 tahun, dan menderita penyakit kronis yang lebih banyak mendapatkan nasihat untuk diit dibandingkan pasien perempuan, usia 18-34 tahun, dan pasien yang sehat. Bertanya dan memberikan nasihat untuk gaya hidup sehat seharusnya dilakukan seorang dokter pada semua pasien tanpa memandang karakteristik pasien. Namun demikian, dalam penelitian ini dan penelitian sebelumnya, terdapat perbedaan karakteristik pasien yang ditanya dan dinasihati meskipun tidak bermakna secara statistik.

Pengingatan kembali pentingnya dokter untuk bertanya dan memberikan edukasi dalam bentuk nasihat atau konseling tentang gaya hidup dapat diberikan dalam kegiatan pendidikan berkelanjutan dan pembelajaran yang perlu dikuatkan serta masuk ke dalam kurikulum wajib untuk calon dokter. Hal tersebut penting untuk dilakukan dokter agar pasien termotivasi menjalankan gaya hidup sehat. Seseorang yang melaporkan menerima nasihat tentang perubahan pola makan pada saat bertemu dengan dokter di pelayanan kesehatan dilaporkan lebih mengubah pola makannya daripada yang tidak dinasihati (24). Di Eropa, dokter pelayanan primer mempunyai peran penting dalam mendiskusikan gaya hidup dengan pasien (12). Penelitian tentang nasihat medis dan penatalaksanaan diabetes pada masyarakat Mexico Amerika, kulit putih, dan hitam nonhispanik di Amerika menemukan bahwa pasien yang melaporkan telah diberi nasihat medik berkaitan dengan penatalaksanaan diabetes, berpeluang 4-8 kali untuk 
mengubah perilakunya. Nasihat medis yang diberikan oleh dokter kepada pasien melalui komunikasi yang efektif akan memuaskan kedua belah pihak sehingga kepuasan akan membawa kepatuhan terhadap nasihat dokter (18).

Pasien perempuan, tidak menikah, dan didiagnosis dokter sebagai pasien diabetes, lebih mempersepsikan bahwa kebiasaan mengonsumsi sayur dan buah berhubungan dengan penyakit yang dideritanya. Pasien yang kurang mengonsumsi sayur dan buah serta yang mengonsumsi sayur dan buah 3 porsi sehari adalah yang lebih mempersepsikan bahwa konsumsi buah dan sayur berhubungan dengan penyakit yang dideritanya dibandingkan pasien yang mengonsumsi sayur dan buah lebih dari 3 porsi sehari. Persepsi tentang hubungan antara konsumsi sayur dan buah dengan penyakit yang diderita diperlukan untuk dapat melakukan pola konsumsi sayur dan buah seperti yang disarankan dalam PUGS (19). Dalam teori Health Belief Model (25), kerentanan tubuh dan keparahan penyakit merupakan ancaman sehingga bila seseorang merasakan manfaat untuk melakukan tindakan pencegahan lebih kuat daripada ancamannya, maka seseorang tersebut akan melakukan tindakan pencegahan. Berdasarkan hasil penelitian ini, terlihat bahwa pasien yang didiagnosis diabetes dan memiliki keluhan tekanan darah tinggi adalah mereka yang mengonsumsi sayur dan buah lebih dari 3 porsi sehari. Hal ini menunjukkan bahwa kerentanan terhadap diri memicu seseorang untuk melakukan tindakan pencegahan.

Penelitian ini mempunyai keterbatasan dalam generalisasi hasil karena sampling dalam penelitian diambil dengan kuota sampling meskipun telah mempertimbangkan keterwakilan wilayah. Wawancara pada pasien berdasarkan kuesioner terstruktur yang secara ideal dibacakan sesuai dengan pertanyaan yang tertulis, tetapi karena beberapa pasien berbahasa Jawa, pertanyaan diterjemahkan secara langsung pada saat dilakukan wawancara. Penerjemahan secara langsung dapat menimbulkan bias respons. Variabel konsumsi sayur dan buah hanya berdasarkan pada pertanyaan tentang frekuensi dan bukan food recall maupun FFQ.

\section{SIMPULAN DAN SARAN}

Tidak ada perbedaan antara pasien dan dokter dalam melaporkan tentang dokter bertanya konsumsi sayur dan buah. Namun, dokter melaporkan lebih banyak daripada pasien dalam menasihati pasien untuk mengonsumsi sayur dan buah. Sebagian besar pasien berpendapat bahwa dokter seharusnya menanyakan kebiasaan pasien dalam mengonsumsi sayur dan buah. Anamnesis atau bertanya untuk menggali riwayat penyakit sangat diperlukan sebagai dasar untuk memberikan nasihat. Oleh karena itu, kemampuan menelusuri gaya hidup perlu ditekankan dalam pembelajaran di fakultas kedokteran. Bila dimungkinkan, dokter mendapatkan insentif bila memberikan edukasi gaya hidup dalam skema SJSN sehingga memotivasi dokter untuk rutin bertanya dan memberikan nasihat.

Pasien yang memiliki masalah berat badan, pasien dengan gangguan pencernaan serta pasien dengan diabetes dan gangguan kardiovaskular lebih ditanya dan dinasihati oleh dokter untuk mengonsumsi sayur dan buah. Demikian pula jika pasien perempuan, janda atau duda, berusia kurang dari 45 tahun, dan tidak mengonsumsi sayur dan buah setiap hari, lebih banyak ditanya dan dinasihati oleh dokter. Persepsi pasien terhadap hubungan antara penyakit yang diderita dengan konsumsi sayur dan buah lebih ditemukan pada pasien diabetes, perempuan, tidak menikah, usia kurang dari 45 tahun, dan tidak mengonsumsi sayur dan buah setiap hari. Pasien diabetes lebih sering mengonsumsi sayur dan buah dibandingkan pasien hipertensi.

Kampanye tentang porsi sayur dan buah yang dianjurkan untuk dikonsumsi setiap hari perlu lebih intensif. Masyarakat perlu memahami kaitan antara mengonsumsi sayur dan buah dan kemungkinan menderita penyakit tidak menular. Pesan yang disampaikan pada masyarakat perlu menarik, detail namun sederhana, dan ditayangkan berulang agar masyarakat lebih paham terhadap pesan tersebut. Advokasi pada pemerintah perlu dilakukan agar pertanian dan perdagangan sayur dan buah diberi subsidi sehingga harga sayur dan buah dapat dijangkau.

\section{UCAPAN TERIMA KASIH}

Penelitian ini dibiayai dengan Dana Masyarakat Fakultas Kedokteran Universitas Gadjah Mada tahun 2011. 


\section{RUJUKAN}

1. World Bank. Indonesia health sector review. Washington: The World Bank, December; 2012.

2. Kemenkes RI. Riskesdas 2007. Jakarta: Balitbangkes Kemenkes RI, Kemenkes RI; 2008.

3. Kemenkes RI. Riskesdas 2010. Jakarta: Balitbangkes Kemenkes RI, Kemenkes RI; 2010.

4. Djaya S. Transisi epidemiologi di Indonesia dalam dua dekade terakhir dan implikasi pemeliharaan kesehatan menurut Survei Kesehatan Rumah Tangga, Surkernas, Riskesdas (19862007). Bul Penelit Kesehat 2012;40(3):142-53.

5. WHO. World health statistics 2011. Geneva: World Health Organization; 2012.

6. Beaglehole R, Horton R. Chronic diseases: global action must match global evidence. Lancet 2010;376(9753):1619-21.

7. WHO. NCD country profile. Geneva: World Health Organization; 2012.

8. Noordman J, Verhaak P, van Dulmen S. Discussing patient's lifestyle choices in the consulting room: analysis of GP-patient consultations between 1975 and 2008. BMC Family Practice [series online] 2010 [cited 30 December 2013];11:87. Available from: URL: http.//www. biomedcentral.com/1471-2296/11/87

9. WHO. Assessing national capacity for the prevention and control non communicable disease. Report of the 2010 Global Health Survey. Geneva: World Health Organization; 2012.

10. Affiansyah N, Mudjianto TT, Hidayat TS, Hennina, Luciasari E, Fuada N. Pengembangan pesan-pesan gizi seimbang dalam PUGS yang lebih praktis digunakan petugas gizi lapangan. PGM 2003;26(2):35-41.

11. Fertman C,Allensworth DD. Health promotion programs. San Fransisco, USA: Jossey-Bass, A Wiley Imprint; 2010.

12. Koster FRT, Verheijden MW, Baartmans JA. The power of communication. Modifying behavior: effectively influencing nutrition patterns of patients. Eur J Clin Nutr 2005;59(1):S17-22.

13. Cole SA, Bird J. The medical interview. St. Louis: Mosby; 2000.

14. Brewster JM, Victor C, Ashley MJ. Views of Ontarians about health professionals' smoking cessation advice. Can J Public Health 2007;98(5):395-9.

15. Claramita M, Prabandari YS, Dalen Jv, Vleuten Cv. Developing and validating a guideline on doctor-patient communication for Southeast Asian context. SEAJME 2010;4(2):23-30.

16. Berry LL, Parish JT, Janakiraman R, Russell LO, Couchman GR, Reyburn WL, Grissel J. Patients' commitment to their primary physician and why it matters. Ann Fam Med [series online] 2008 [cited 30 December 2013];6(1):6-13. Available from: URL: http.//www.annfamed.org

17. Milder IEJ, Blokstra A, Groot J de, Dulmen S van, Bemelmans WJE. Lifestyle counseling in hypertensionrelated visits - analysis of video-taped general practice visits. BMC Family Practice 2008;9:58.

18. Vaccaro JA, Feaster DJ, Lobar SL, Baum MK, Magnus M, Huffman FG. Medical advice and diabetes selfmanagement reported by Mexican-American, Black- and White-non-Hispanic adults across the United States. BMC Public Health [series online] 2012 [cited 30 December 2013];12:185. Available from: URL: http.// www.biomedcentral.com/1471-2458/12/185

19. Depkes RI. Pedoman umum gizi seimbang (panduan untuk petugas). Jakarta: Depkes RI Direktorat Jenderal Bina kesehatan Masyarakat Direktorat Gizi Masyarakat; 2003.

20. Howe M, Leidel A, Krishnan S, Weber A, Rubenfire M, Jackson EA. Patient-related diet and exercise counseling: do providers' own lifestyle habits matter? Prev Cardiol 2010;13(4):180-5.

21. Heaton PC, Frede SM. Patients' need for more counseling on diet, exercise, and smoking cessation: results from the National Abulatory Medical Care Survey. J Am Pharm Assoc 2006;46(3):364-9.

22. Summary of revisions for the 2009 clinical practice recommendations. Diabetes Care 2009;32(Supp1 1):S3-5.

23. Sinclair J, Lawson B, Burge F. Which patients receive advice on diet and exercise? Do certain characteristics affect whether they receive such advice? Can Fam Physician 2008;54(3):404-12.

24. Glanz K. Current theoretical bases for nutrition intervention and their uses. Nutrition in the prevention and treatment of disease-chapter 6. Massachussets, USA: Academic Press; 2011.

25. Glanz K, Rimer BK, Viswanath K. Health behavior and health education. San Fransisco, USA: Jossey-Bass, A Wiley Imprint; 2008. 